\title{
Achievements and Implications of HIV Prevention Programme among In-School Youths: A Systematic Evaluation of HAF II Project in Kogi State, Nigeria
}

\author{
Ademola L. Adelekan ${ }^{1,7}$, Gabriel Musa ${ }^{2}$, Agada Gloria ${ }^{3}$ \\ Matthias Okpanachi ${ }^{4}$, Ogundipe Love ${ }^{5}$, Onoja Johnson ${ }^{6}$, Williams Shaibu ${ }^{2}$, \\ Patrick Adah $^{2}$, Adetunji Adetayo ${ }^{7}$, Oladipupo S. Olaleye ${ }^{7}$, Segun Adeoye ${ }^{8}$, \\ Michael Olugbile $^{8}$, Philomena Omoregie ${ }^{1}$, Aliyu Sani ${ }^{9}$, Emmanuel Alhassan ${ }^{9}$, \\ Tobias John ${ }^{9}$, Oluwakemi Ladeinde ${ }^{9}$ \\ ${ }^{1}$ Blue Gate Public Health Promotion Initiative, Ibadan, Nigeria \\ ${ }^{2}$ Kogi State Agency for the Control of AIDS, Lokoja, Nigeria \\ ${ }^{3}$ New Hope Agency, Lokoja, Nigeria \\ ${ }^{4}$ Youth and Women Empowerment Project, Lokoja, Nigeria \\ ${ }^{5}$ Environmental Development and Family Health Organization, Lokoja, Nigeria \\ ${ }^{6}$ Africa Health Project, Lokoja, Nigeria \\ ${ }^{7}$ Department of Health Promotion and Education, Faculty of Public Health, College of Medicine, University of \\ Ibadan, Nigeria \\ ${ }^{8}$ HIV Programme Development Project, World Bank, Abuja, Nigeria \\ ${ }^{9}$ National Agency for the Control of AIDS, Abuja, Nigeria
}

\begin{abstract}
Background: HIV and AIDS continue to be huge problems especially among youths. Nearly half of the 3.1 million Nigerians living with HIV were between 15 and 24 years old. This intervention project was therefore designed to reduce the incidence and prevalence of HIV among in-school youths (ISYs) in Kogi State, Nigeria. This paper presents the achievements and implications of this intervention.

Methods: Four civil society organizations were engaged under HIV and AIDS Fund (HAF) II project to implement ISYs intervention in 6 out of the 21 Local Government Areas (LGA) in Kogi State. The project was carried out from 2014 to 2016 and implementation was done using HIV Minimum Prevention Package Intervention (MPPI). Data collected were analysed using descriptive statistics with the use of Microsoft Excel.

Results: The total number of community dialogues/advocacy held was eleven over the period of the project and $63.3 \%$ of the influencers that participated in 2014. A total of 69,248 peers were registered in this project and $65.6 \%$ were registered in 2015. Among these, a total of 54165 were reached with HIV education. A total of 9465 $(27.5 \%)$ were counseled, tested and received result between 2013 and 2015; over half of this was done in 2015 (52.2\%). A total of 208 tested positive and were referred for ARV while the prevalence was 2.2\%. Majority (78.2\%) of the registered peers were reached with MPPI.

Conclusion: The high percentage recorded in terms of peers reached with MPPI suggests that the programme was successful. This project should be sustained and extended to other LGAs not covered so as to help reduce the burden of HIV in the state.
\end{abstract}

Keywords:- HIV prevention, HAF II project, In-school youths, Minimum prevention package intervention

\section{BACKGROUND}

In 2013, 35.3 million people are living with HIV with 2.3 million new infections and about $39 \%$ are among young people (15-24) and young women having an especially high risk of acquiring HIV twice as high as the young men. More than two-thirds (70 percent) of people living with HIV live in sub-Saharan Africa, including 88 percent of the world's HIV-positive although this region contains a little more than $12 \%$ of the world population [1]. In Nigeria, the HIV prevalence among 15-24 years old men and women is $2.5 \%$ and $3.1 \%$ respectively [2]. Nearly half of the 3.1 million Nigerians living with HIV were between 15 and 24 years old [3]. Kogi State has an HIV prevalence of about $8.0 \%$ and also shares boundary with Benue State which has the highest HIV prevalence (12.7\%) in Nigeria [4]. This geographical location predisposes Kogi State youths to be more susceptible to HIV/AIDS. Nigerian students within the age range 15-25 years accounts for more than $60 \%$ of new HIV infections. This takes place against a background in which one-third of the country's population of about 160 million are aged 10-24 years [5]. The achievement of the Millennium Development Goal 8 which was 
to combat HIV/AIDS, Malaria and other diseases by 2015 has not been made possible as the prevalence of the disease continued to increase rather than decrease especially among this population. According to the information from African Development [6] gave the indices of Nigerian youth literates to be $43.25 \%$ in the North Eastern Zone, $45.15 \%$ in the North Western Zone, $69.7 \%$ in the North Central Zone, 85.3\% in the South Eastern Zone, $85.65 \%$ in the South Western Zone and $90.45 \%$ in the Southern Zone, this corroborates the fact that school is the best place to capture youths for HIV and AIDS intervention as majority of them go to school. Also, research conducted by [7] showed that teachers favoured school-based sexual and reproductive health interventions for students but are not too comfortable counselling them one on one.

Early sexual debut, non-consensual sex, unprotected sex and multiple sex partners were prevalent sexual risk behaviours predisposing to HIV/AIDS among young people [8]. Socio-cultural practices like alcohol usage, use of pornography, blood swearing covenants, vulnerable sexual practices, cultic practices, early marriages, circumcising females and not circumcising the males all make them more susceptible to HIV [9]. A study carried out by [10] revealed that most youths are involved in unprotected sex despite their awareness of the efficacy of condom and its use. A 2008 study also noted that most youths in Kogi State engaged in high risk sexual activities, such as casual unprotected sex, multiple sexual partners, transactional sex and concurrent sex, with $13.0 \%$ of the female youth population having had sex before attaining the age of 15 years while $35 \%$ of their male counterparts reported likewise [11]. In addition, the proportion of men and women reporting high risk sexual intercourse in the state is very high ( $19 \%$ women \& $52 \%$ men), while $28 \%$ of men were reported to have paid for sex on several occasions in the year prior to the report [11]. A study carried out by [12] identified that peer education is an effective intervention approach among in-school youths. Adeomi et al.,[12] stated this because the knowledge of the study group increased as compared to the control group as it regards HIV/AIDS. Population Council made available the report of various interventions carried out by several non-governmental organizations on youths with focus on HIV reduction [13]. The interventions included education, voluntary counselling and testing, free provision and distribution of condoms. It was found out that behavioural change intervention produced the best result as it reduced the prevalence of HIV and AIDS among the population. As World Bank [14] has reported that education is associated with the actualization of most of the millennium development goals, it is highly imperative to address the impact of HIV and AIDS in the educational sector in Nigeria. Hence this article presents the achievements and implications of HIV prevention programme carried out among in-school youths (ISYs) in Kogi State, Nigeria.

\subsection{Study Design and Scope}

\section{METHODOLOGY}

This was an intervention project designed to reduce the incidence and prevalence of HIV among inschool youths in Kogi State. The project was carried out between 2014 and 2016.

\subsection{Study Area}

Kogi State was created in 1991 from the eastern part of the then Kwara State and western part of the then Benue State. The state occupies the central part of Nigeria and it is unique for serving as the belt for the two major rivers in Nigeria; Niger and Benue, Lokoja is the capital of the state and here the two rivers meet, hence the appellate 'Confluence State'. The state occupies an area of 28, 312.6 square kilometres. It is bounded by ten states and the Federal Capital Territory (FCT). To the north; Niger, FCT and Nassarawa, to the west; Kwara, Ekiti, Ondo, Edo and Delta, while to the east; Benue, Anambra and Enugu States. Kogi State is actually the only Nigerian State that shares boundary with as much as ten States. The state contains 239 wards in 21 local governments and 3 senatorial districts. The population as at 2006 was 3, 478,029. Males make up 46.8\% and females 53.2\% (National Population Commission, 2006). The state consists of three main tribes which are Igala, Ebira and Okun-Yoruba. There are also other minority tribes like Nupe, Ogori, Bassa-komo, Bassa-Nge, Egbira-koto among others. The state is highly heterogeneous due to its location. Agriculture is the main occupation of its inhabitants.

\subsection{Study Population}

The study population was in-school youths from ages 15-24 years in Kogi State. Youths who were enrolled in the selected schools in the state for at least a year prior to the study and were between the ages of 1524 years were selected and all those who did not fall within the inclusion criteria were excluded.

\subsection{Sample size}

The estimated target population was 34,362 in school youths. The sample was selected in 6 out of 21 Local Government Areas (LGAs) in Kogi State. The 6 LGAs included are Ankpa, Kabba/Bunu, Idah, Lokoja, Adavi and Kogi. 
Description of the Project

A total of four civil society organizations (CSOs) were engaged to implement HIV in-school youths (ISYs) interventions these are Environmental Development and Family Health Organization (EDFHO), New Hope Agency (NHA), Youth and Women Empowerment Project (YAHWEP) and Africa Health Project (AHP). These CSOs through the Kogi State Agency for the Control of AIDS (KOSACA) under the HIV and AIDS fund (HAF) II project intervention reached ISYs through direct social services to promote normative change. The CSOs focused on a unified structured approach, working closely with community stakeholders and school heads. The CSOs also used well defined and proven methodologies to reach the ISYs with the aim to improve their wellbeing and to remain relevant in a healthy and socially supportive environment. Emphasis was placed on heightening the perception of self-efficacy to prevent HIV, mobilization of communities to change social, cultural norms and value to ones that minimize their vulnerability to HIV. The CSOs also strategically integrated all HIV and health services to achieve maximal and efficient synergy in the prevention of HIV through a well detailed monitoring and evaluation plan. This was possible through advocacy visits, community leaders' dialogues, peer review meetings, free HIV counseling and testing (HCT), outreaches and referral services. The participating stakeholders were; PLHIV (support groups), community groups, KOSACA, CSOs HIV team, local government officials and traditional rulers.

\subsection{Baseline survey}

Baseline survey was conducted in selected secondary schools in Lokoja LGA in May 2014 to assess the knowledge of young men and women, their perception and practice with regards to issues related to sexual health including HIV/AIDS. The assessment was aimed to provide information in other to improve the content and quality of programme interventions in sexual health, offered to young men and women. Qualitative and quantitative approaches were used for data collection and purposive sampling method was used in selecting respondents.

\subsection{Advocacy and Coordination Meeting}

Following the findings and recommendation from the baseline, teams from the CSOs paid advocacy visits to different community actors who are principals of various schools, the local government chairmen, traditional rulers of the selected towns and health facilities in the locality. This gave the organizations an opportunity to familiarize themselves with the communities and the facilities. In designing an effective mechanism for project implementation in the communities, the CSOs through coordination effectively created an enabling environment for a successful project implementation that aided the various visits and intervention.

\subsection{Intervention Activities/Strategies}

The Minimum Prevention Package Intervention (MPPI) was used for the implementation of the programme. These strategies were organized into three levels of interventions which were; structural, behavioural and biomedical.

\subsubsection{Structural Intervention}

\subsubsection{Community dialogue}

The CSOs conducted community dialogue in communities where the project was implemented. Various community stakeholders were selected ranging from community chiefs, market women and men, youth leaders, Motorcycle riders' association representatives, religious leaders etc. In implementing effective community dialogue, everyone was given a voice and space through which they could articulate their feelings and concerns and collectively came up with answers that are pertinent and meaningful.

\subsubsection{Community Sensitization}

In strengthening and supporting institution to strategically linking HIV prevention intervention through the project, the CSOs conducted series of meetings and promoted linkages through meeting between staffs of the medical centre and the project team that enhanced collaboration and experience sharing and also conducted community dialogue meetings to keep the groups abreast with HIV/AIDS and TB management, care and support. Also, the CSOs encouraged effective networking and leveraging of ideas and support.

2.8.2 Behavioural Intervention

2.8.2.1 Recruitment of peer educators

Following the advocacy for a smooth project take off was identification of the right category of people to aid the propagation of HIV prevention intervention, hence the enrollment of peer educators (PEs) on the 
project. The PEs were identified, enrolled and registered for the project. This was successful through school visit, local government headquarters visit and community.

\subsubsection{Peer session meeting}

The trained peer educators carried out peer/cohort sessions (meetings) with their peers in their various communities and schools to enhance support for prevention of sexual transmission messages for effective compliance towards reaching the project goal and objectives. The meetings were done within the range of 2-3 months with the frequency contact ranging between 6 to 9 times. The intervals of meeting days ranged between 10 to 15 days.

\subsubsection{Peer education training}

ISYs were trained as Peer educators in selected secondary schools. There was emphasis on sexual transmission prevention strategy which was designed to focus specifically on unmarried youth engaging in unprotected sex and multiple sexual partnerships.

\subsubsection{Biomedical Intervention}

HIV Counseling and Testing (HCT)

The CSOs conducted a stakeholder's forum in the communities to sensitize and conduct HCT. The HCT was conducted by trained Counsellor Testers and data were documented using HIV client intake form. During the testing, counseling services on HIV were also provided to clients.

2.9 Monthly Monitoring and Evaluation visit to project sites

Desk review for the collated data from the trained PE was conducted to ensure data quality for effective compliance to project goals and objectives.

\subsection{Data Analysis}

Data were collected using various but uniform data collection and reporting tools. The data were collected from various activities carried out under structural intervention, behavioural intervention and biomedical interventions. The data were entered into DHIS2 platform and exported into Microsoft excel. The results were analyzed using Microsoft Excel by comparing frequencies and percentages. They were carefully presented in tables and chart.

\section{RESULTS}

The findings are presented based on the levels of intervention: structural, behavioural and biomedical interventions. The overall target population reached during this intervention was 71830 given a target reached of $209.0 \%$

\subsection{Structural Interventions}

Structural interventions are presented in table 1 . The total number of community dialogues/advocacy held was 11 over the period of 2014-2015. Out of the 11 dialogues, just over half (54.5\%) was held in 2015 while the remaining $45.5 \%$ was held in 2014. Data on the influencers that were involved the community dialogues were also presented in table 1. A total of 412 influencers participated. Majority (63.3\%) of the influencers that participated in community dialogue did so in 2014 while $36.7 \%$ did so in 2015 .

Table 1: Structural Interventions

\begin{tabular}{|c|c|c|}
\hline Period & $\begin{array}{c}\text { Number of community } \\
\text { dialogues }(\boldsymbol{\%})\end{array}$ & $\begin{array}{c}\text { Influencers participating in comm. } \\
\text { Dialogue (\%) }\end{array}$ \\
\hline 2014 & $5(45.5)$ & $261(63.3)$ \\
\hline 2015 & $6(54.5)$ & $151(36.7)$ \\
\hline Total & $\mathbf{1 1}$ & $\mathbf{4 1 2}$ \\
\hline
\end{tabular}

\subsection{Behavioral Intervention}

Data on condom programming was shown in table 2. A total of 24 pieces of female condom were distributed and all were distributed in 2015. Male condoms were majorly distributed in $2015(51.1 \%)$ with (49.0\%) distributed in 2014. Table 2 also contained data on peers registered by the PEs. A total of 69,248 peers were registered in this project and $65.6 \%$ were registered in 2015. Among these, a total of 54165 were reached with HIV education (Table 2) 
Table 2: Behavioural Intervention

\begin{tabular}{|c|c|c|c|r|r|r|c|c|}
\hline Period & \multicolumn{2}{|l|}{$\begin{array}{l}\text { Number of peers } \\
\text { registered N (\%) }\end{array}$} & \multicolumn{2}{c|}{$\begin{array}{c}\text { Number of persons } \\
\text { reached with HIV } \\
\text { Education N (\%) }\end{array}$} & \multicolumn{2}{|c|}{$\begin{array}{c}\text { Number of condoms } \\
\text { distributed }\end{array}$} \\
\cline { 2 - 9 } & Female & Male & Total & Female & Male & Total & $\begin{array}{c}\text { Female } \\
\text { Condom } \\
(\%)\end{array}$ & $\begin{array}{c}\text { Male } \\
\text { Condom } \\
(\%)\end{array}$ \\
\hline \multirow{2}{*}{2014} & 11712 & 11126 & 22838 & 9031 & 8592 & 17623 & $0(0.0)$ & 22751 \\
& $(31.9)$ & $(33.6)$ & $(33.0)$ & $(30.5)$ & $(35.0)$ & $(48.2)$ & & $(49.0)$ \\
\hline \multirow{2}{*}{2015} & 24458 & 21952 & 46410 & 20620 & 15922 & 36542 & $24(100.0)$ & 23718 \\
& $(67.6)$ & $(66.4)$ & $(67.0)$ & $(69.5)$ & $(65.0)$ & $(51.8)$ & & $(51.1)$ \\
\hline Total & $\mathbf{3 6 1 7 0}$ & $\mathbf{3 3 0 7 8}$ & $\mathbf{6 9 2 4 8}$ & $\mathbf{2 9 6 5 1}$ & $\mathbf{2 4 5 1 4}$ & $\mathbf{5 4 1 6 5}$ & $\mathbf{2 4}$ & $\mathbf{4 6 4 6 9}$ \\
\hline
\end{tabular}

\subsection{Biomedical Interventions}

Data on number of persons, who were counseled, tested and received result (CTR) are presented in table 3. A total of 9,465 were CTR between 2014 and 2015; over half of this was done in 2015 (52.3\%). Among these, 208 persons were tested positive showing HIV prevalence of $2.2 \%$ (Fig 1). On the number of persons referred for STI services, a total of 5 persons were referred and all 5 were referred in 2015. The data available also showed that a total of 4 persons received STI services with all 4 receiving STI services in 2015 as well. This was similar for the number of persons that went for STI follow-up. Four persons went for follow-up and all 4 did so in 2015. Selected items from the biomedical interventions were presented by gender in table 3 .

Table 3: Biomedical Interventions

\begin{tabular}{|c|c|c|c|c|c|c|c|}
\hline \multirow[t]{2}{*}{ Period } & \multicolumn{3}{|c|}{ No CTR (\%) } & \multirow{2}{*}{$\begin{array}{c}\text { No tested } \\
\text { positive } \\
(\%)\end{array}$} & \multirow{2}{*}{$\begin{array}{c}\text { No } \\
\text { referred } \\
\text { for STI } \\
\text { services } \\
(\%)\end{array}$} & \multirow{2}{*}{$\begin{array}{c}\text { No of } \\
\text { received } \\
\text { STI } \\
\text { services } \\
(\%)\end{array}$} & \multirow{2}{*}{$\begin{array}{c}\text { No went } \\
\text { for STI } \\
\text { follow-up } \\
(\%)\end{array}$} \\
\hline & Female & Male & Total & & & & \\
\hline 2014 & $\begin{array}{c}2659 \\
(55.1)\end{array}$ & $\begin{array}{c}2380 \\
(51.3)\end{array}$ & $\begin{array}{c}5039 \\
(53.2)\end{array}$ & $\begin{array}{c}94 \\
(45.2)\end{array}$ & $\begin{array}{c}0 \\
(0.0)\end{array}$ & $\begin{array}{c}0 \\
(0.0)\end{array}$ & $\begin{array}{c}0 \\
(0.0)\end{array}$ \\
\hline 2015 & $\begin{array}{c}2167 \\
(44.9)\end{array}$ & $\begin{array}{l}2259 \\
(48.7)\end{array}$ & $\begin{array}{l}4426 \\
(46.8)\end{array}$ & $\begin{array}{c}114 \\
(54.8)\end{array}$ & $\begin{array}{c}5 \\
(100.0)\end{array}$ & $\begin{array}{c}4 \\
(100.0)\end{array}$ & $\begin{array}{c}4 \\
(100.0)\end{array}$ \\
\hline Total & 4826 & 4639 & 9465 & 208 & 5 & 4 & 4 \\
\hline
\end{tabular}

\subsection{Coverage of MPPI, HCT and Prevalence of HIV}

The percentage of persons reached with MPPI out of registered peers was $72.8 \%$. The total percentage reached with HCT was $27.5 \%$ while the prevalence of HIV was $2.2 \%$ (Fig. 1).

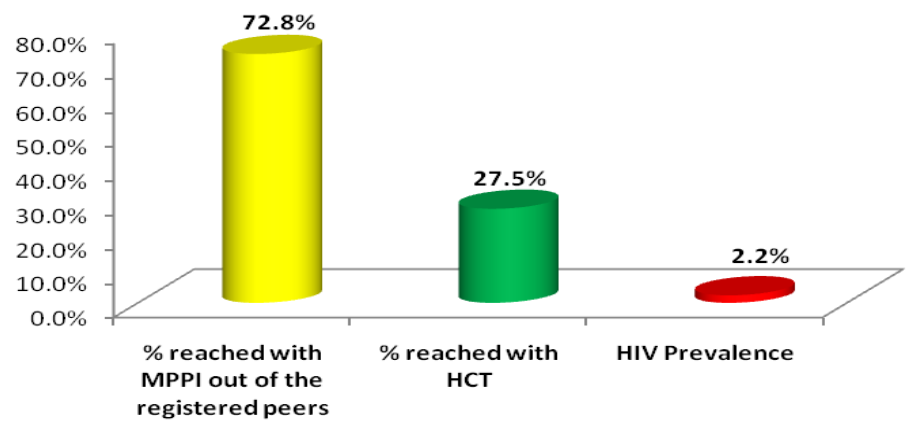

Figure 1: Coverage of MPPI, HCT and Prevalence of HIV

IV. DISCUSSION

The use of structural intervention in this project especially the community dialogue has contributed immensely to the success of this project. More community dialogues were done in 2015 as against more 
influencers that were involved in 2014. This showed that number of influencers had little to do with the dialogues. Community dialogues have also been used by the German government in collaboration with the Nelson Mandela to fight the scourge for HIV/AIDS among youths [15]. The community dialogues done in this study were vital to facilitate the acceptability of the various interventions and it certainly helped in generating the necessary response from the target population. This agrees with the Guidelines for Conducting Community Dialogue put forward by the National AIDS Commission of Malawi [16].Condom programming and peer educators were the major behavioural interventions carried out by the CSOs. These are similar to the Geraçao Biz program done in Mozambique. Trained peer educators were used to reach young people and condoms were also distributed [17]. In this project, all condoms were distributed in 2015. On the peer educators more were registered in 2015. The percentage for peers increased substantially from 2013 to 2015 . The data in this section generally suggests that more was done in 2015 than any other year. The high coverage of condom programming in this study is in variance with the notion put forward by [18] in their study among youths in Ekiti state, Nigeria, where they compared in-school youths and out-of-school youths, it was showed that condom use was less among the ISY population. In this study, though coverage was high, it might not translate to use. However, it is a step in the right direction should these population engage in risky sexual behaviour. Peer-led approach was also used in a similar program, USAID/Ethiopia In-School Youth HIV Prevention Program [19]. Peer education presents a good opportunity for young people such as the target population in this study to help develop and make effective informed decisions on issues relating to HIV/AIDS. The biomedical intervention revealed that there were three major interventions with data on receipt of STI services and follow-up coming from the health centres. Just as it was noticed in the structural and behavioural interventions, more was done in 2015 as more persons were referred for STI and ARV in 2015. This was with the exception of HCT where more than half were counseled, tested and got result in 2015. In a study conducted by [20] among eight secondary schools in Kenya, it was shown that only $24.7 \%$ of respondents had undergone HCT which is comparable to $27.5 \% \%$ covered in the current study.

V.

IMPLICATIONS FOR PROGRAMMING

The results of this intervention have great implications for programming. Series of strategies could be used to sustain the success stories recorded in this programme. The challenges could in similar way be surmounted. Positive reaction to HIV prevention messages among community members as well as eager participation in community dialogue meeting could be encouraged as a way of ensuring the success of similar programmes in the future. This could be done by continuous engagement of community leaders and gatekeepers. Generally, proper community entry is expected to facilitate the implementation of a programme such as this; hence the success recorded. This will also go a long way in ensuring stakeholders support for the programme. The major challenges documented during this study was shortage of HIV testing kits, difficulty in getting facilities to help with kits and lack of IEC materials, this should have inadvertently affected the HCT coverage of $27.5 \%$. To avoid such problems in future, there should be a strong support from the government to help compliment the efforts of donor agencies. This will go a long way to help reach a larger set of beneficiaries and by so doing reduce the burden of the disease. One of the reasons why there was shortage of HIV testing kits was the fact that there was an unprecedented large turnout of people. This could be planned for in future. Appropriate measures could be put in place to checkmate having more people than the resources available.

\section{VI.}

\section{CONCLUSION}

The high percentage recorded in terms of peers reached with MPPI suggests that the programme was successful. Behavioural change intervention on HIV and HIV counselling and testing services needs to be intensified in the state especially in the local government areas not covered in the current project so as to reduce the burden of HIV in the state. The government could sustain this project or similar projects through the contribution of materials, finance and enabling environment for organizations and donors. More interventions should be done by using peers as it tends to have more impact as shown in during this project.

\section{ACKNOWLEDGEMENT}

The evaluation team wishes to acknowledge the World Bank and the National Agency for the Control of AIDS (NACA) for making available the funding for the conduction of the evaluation programme, the dissemination of results and the writing up of the article.

\section{REFERENCES}

[1] AIDS 2014. Global Fact Sheet: HIV/AIDS.

[2] Federal Ministry of Health [Nigeria]. 2013. National HIV/AIDS and Reproductive Health Survey, 2012 (NARHS Plus II 2012). Federal Ministry of Health Abuja, Nigeria.

[3] National Agency for the Control of AIDS (NACA). 2010. HIV Sentinel Survey (HSS). 
[4] United States Embassy in Nigeria. 2011. Nigeria HIV Fact Sheet.

[5] National Population Commission. 2007. Final Result of the 2006 Census. Abuja: National Population Commission

[6] African Development Bank Group. Growth, Poverty and Inequity Nexus: Overcoming Barriers to Sustainable Development. African Development Report 2015

[7] Aransiola, J.O., Asa, S., Obinjuwa, P., Olanrewaju, O., Ojo O.O. and Fatusi A.O. 2013. Teachers' Perspectives on Sexual and Reproductive Health Interventions for in- $\quad$ school

[8] Isichei, C., Okolo, S.N. and John, C. 2014. Sexual risk behavior and HIVInfection among Adolescents inSecondary Schools in Jos, Nigeria. Niger J Paed. 41(2): 86 -89

[9] Conjoh, A.M., Zhou, Z. and Xiong J. 2011. Sociocultural factors affecting the spread of HIV/AIDS among adolescents in Sierra Leone. The Social Sciences 6(4): 269-276

[10] Agweda, T.O., Dibua, V.A. and Eromonsele, A.O. 2010. Attitude of Youths towards the Use of Condom in Heterosexual Intercourse in Ekpoma Nigeria. Journal of Social Science, 24(3): 169176

[11] National Agency for the Control of AIDS. 2010. National Research Agenda on HIV/AIDS in Nigeria 2010-2015. Abuja, the Presidency.

[12] Adeomi, A.A., Adeoye, O.A., Asekun-Olarinmoye, E.O., Abodunrin, O.L., Olugbenga-Bello, A.I. and Sabageh, A.O. 2014. Evaluation of the Effectiveness of Peer Education in Improving HIV Knowledge, Attitude, and Sexual Behaviours among In-School Adolescents in Osun State, Nigeria. AIDS Research and Treatment. Article ID 131756

[13] Population Council. 2015. "Annotated bibliography of Nigerian Youth-Focused HIV and Sexual And Reproductive Health Project publications (grey literature).” Abuja, Nigeria: $\quad$ Population Council.

[14] World Bank. 2002. Education and HIV/AIDS: a window of hope. Washington, DC: World Bank.

[15] German Federal Ministry for Economic Cooperation and Development. 2016. Promoting Community dialogue to tackle HIV and AIDSs.

[16] National AIDS Commission, Malawi. 2007. Guidelines for Conducting Community Dialogue. Available at www.aidsmalawi.org.mw

[17] Pathfinder International Mozambique. 2004. Scaling Up Youth HIV/AIDS Prevention: Geração Biz Project.

[18] Fagbamigbe, A. F., Adebowale, A. S. and Olaniyan, F. A. A Comparative Analysis of Condom Use among Unmarried Youths in Rural Community in Nigeria. Public Health Research. 2016 1(1): 8-16

[19] FHI360. 2016. USAID/Ethiopia In-school Youth HIV Prevention Programme. Available at www.fhi360.org/projects/usaidethiopia-school-youth-isy-hiv-prevention-program

[20] Obare, F., Birungi, H., Wanjiru, M., Baiyley, S., Kiunjuri, J., Omondi, M., Burnet, R. and Deacon B. 2012. Positive Action for HIV in Schools in Kenya. APHIA II OR Project in Kenya. Population Council: Nairobi, Kenya. 